\title{
Transventricular off-pump anterior mitral leaflet augmentation: First in human
}

Stefano Salizzoni, MD, ${ }^{\mathrm{a}}$ Matteo Marro, MD, ${ }^{\mathrm{a}}$ Alessandro Vairo, MD, ${ }^{\mathrm{b}}$ Walter Grosso Marra, MD, Giovanni Speziali, MD, FECTS, ${ }^{c}$ and Mauro Rinaldi, MD, $\mathrm{PhD}^{\mathrm{a}}$ Torino, Italy, and Greensburg, $\mathrm{Pa}$

From the ${ }^{\mathrm{a} D i v i s i o n}$ of Cardiac Surgery, Department of Surgical Sciences, Città della Salute e della Scienza di Torino, University of Turin, Torino, Italy; the ${ }^{\mathrm{b}}$ Division of Cardiology, Department of Medical Sciences, Citta della Salute e della Scienza di Torino, University of Turin, Torino, Italy; and ${ }^{\mathrm{c}}$ Excela Health System, Greensburg, Pa.

Disclosures: Drs Salizzoni and Rinaldi are surgical proctors for NeoChord, Inc. Dr Vairo is an echocardiography proctor for NeoChord, Inc. Dr Speziali is a cofounder and stockholder of NeoChord, Inc. All other authors have nothing to disclose with regard to commercial support.

Received for publication Dec 6, 2018; revisions received Jan 25, 2019; accepted for publication Feb 5, 2019; available ahead of print March 25, 2019.

Address for reprints: Stefano Salizzoni, MD, Università degli Studi di Torino, San Giovanni Battista "Molinette"

Hospital, Corso Bramante 88-90, 10126 Torino, Italy (E-mail: salizzonis@gmail.com).

J Thorac Cardiovasc Surg 2019;158:e133-5

$0022-5223 / \$ 36.00$

Copyright (C 2019 by The American Association for Thoracic Surgery

https://doi.org/10.1016/j.jtcvs.2019.02.027

- Video clip is available online.

Transventricular, off-pump, minimally invasive neochord implantation is a technique that has been proved to be safe and effective in treating patients with degenerative

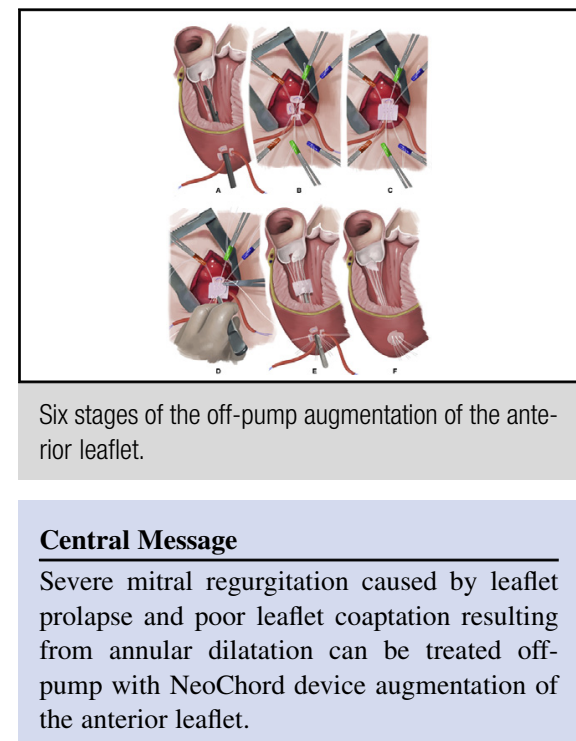

See Commentary page e137.
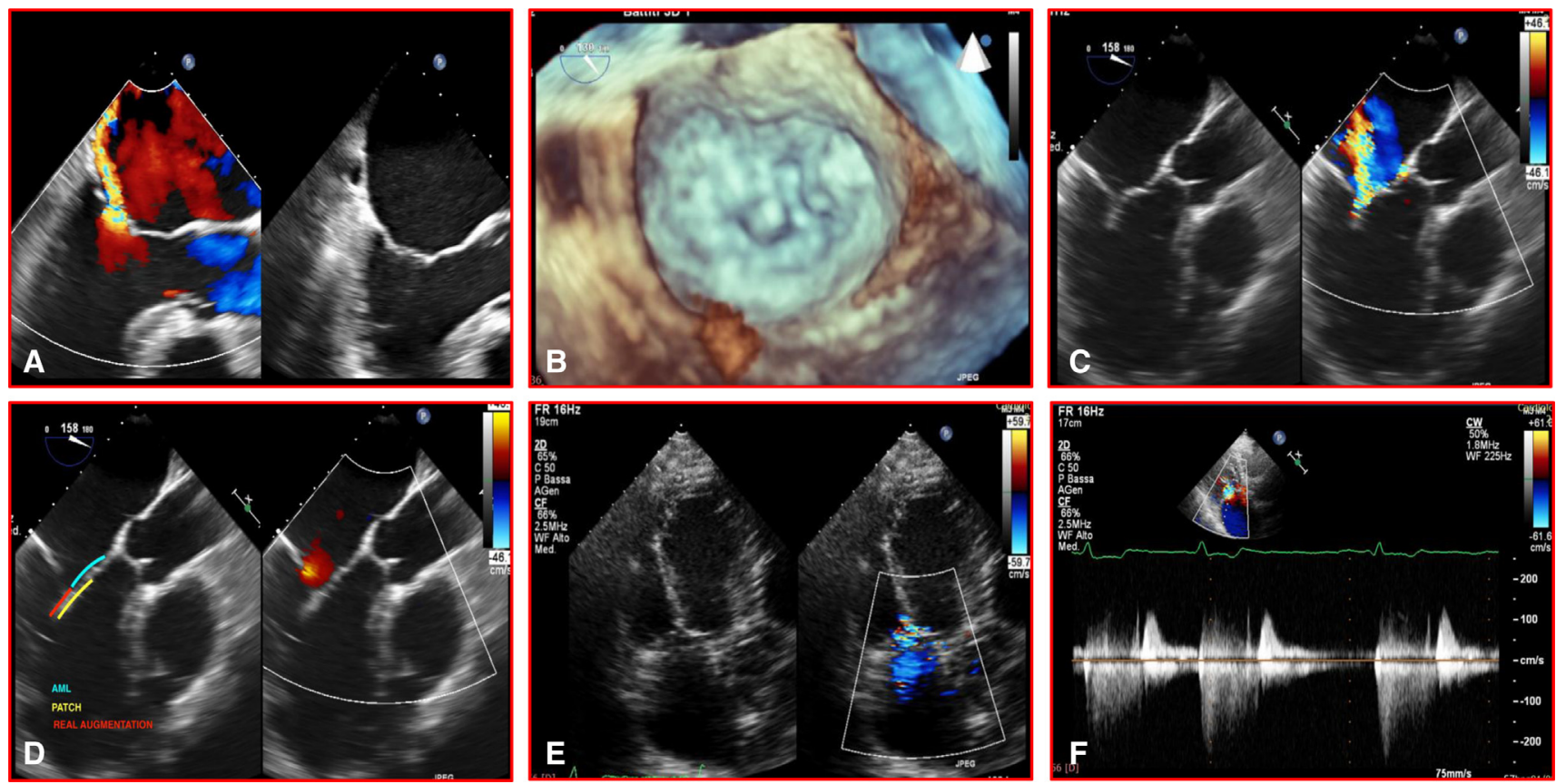

FIGURE 1. A, Transesophageal echocardiography shows severe mitral regurgitation caused by anterior leaflet prolapse and shortening of the leaflets. B, Three-dimensional transesophageal echocardiography mitral valve surgical view with evidence of central anterior leaflet prolapse. C, Transesophageal echocardiography of the final result with neochords and patch placed shows residual mild to moderate mitral regurgitation with reduction of vena contracta and very low proximal isovelocity surface area radius. D, Morphologic imaging of patch and neochords. E, Nine-month follow-up transthoracic echocardiography shows stable residual mitral regurgitation. F, Continuous Doppler mitral flow with evidence of residual mild to moderate mitral regurgitation. 

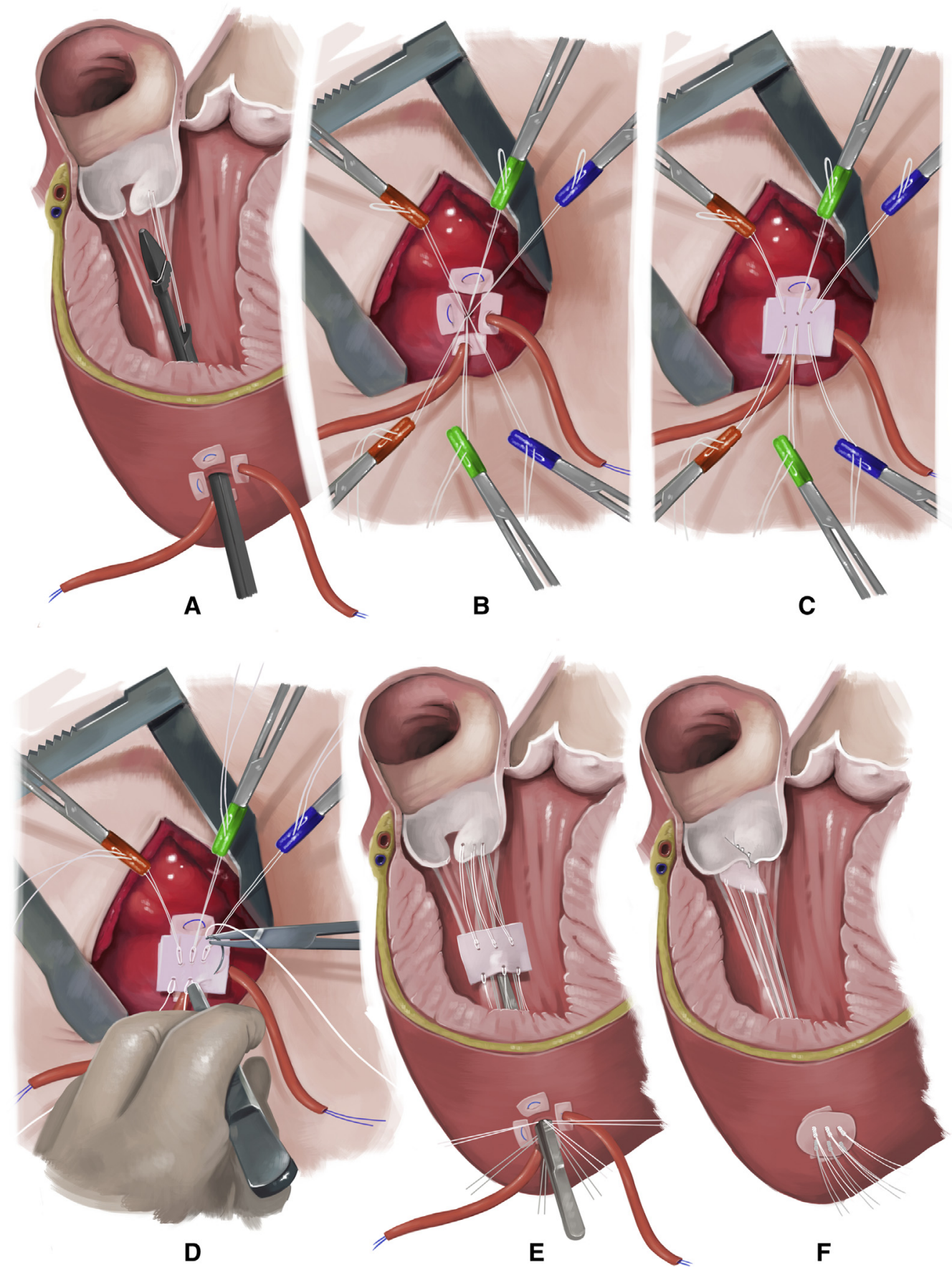

FIGURE 2. A, Insertion of the NeoChord DS1000 device (NeoChord, Inc, Eden Prairie, Minn) through a left minithoracotomy and a posterolateral ventriculotomy to sequentially release 3 expanded polytetrafluoroethylene chords to the free edge of the prolapsing A2. B, The loop and the end of each single expanded polytetrafluoroethylene chord are secured with colored mosquito surgical hemostat forceps. C, The loop and the end of each neochord are then secured to one of the long sides of a properly shaped rectangular pericardial patch. D, The chords attached to the anterior leaflet are now looped, and 3 more chords are then sutured to the other long side of the patch, which becomes the new free edge of the anterior mitral leaflet. E, The patch is then hoisted, driven with the help of forceps, inside the left ventricle by gently pulling on the 3 neochords, until it is positioned against the ventricular side of the anterior leaflet. F, The final result with the new augmented anterior leaflet. (Figure designed by Fabrizio Lavezzi.)

mitral regurgitation caused by leaflet prolapse or flail. ${ }^{1-4}$ Annular dilatation, or poor coaptation potential as a result of short or retracted leaflets, can limit the success of the procedure. We describe here a case of implantation of artificial neochords and patch augmentation of the anterior mitral leaflet with the NeoChord DS1000 system 


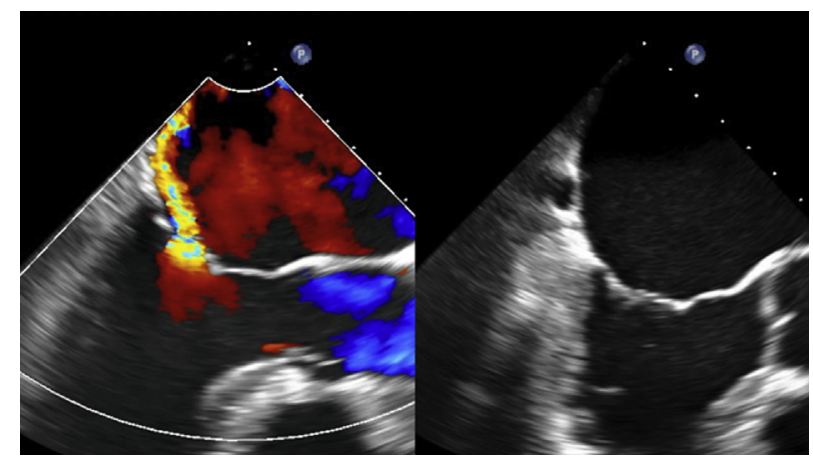

VIDEO 1. Video shows all principal steps of the procedure. $C A B G$, Coronary artery bypass grafting; $A M L$, anterior mitral leaflet. Video available at: https://www.jtcvs.org/article/S0022-5223(19)30460-X/fulltext.

(NeoChord, Inc, Eden Prairie, Minn) under real-time guidance by transesophageal echocardiography.

A 76-years-old man came to our attention for angina and dyspnea at rest (New York Heart Association class IV). In 2001 he underwent quadruple coronary artery bypass grafting. Coronary angiography performed 4 days before the intervention showed patent grafts. Transesophageal echocardiography showed severe mixed mitral regurgitation from both an anterior leaflet prolapse and a central functional component caused by shortened leaflets (Figure $1, A$ and $B$ ).

Because of the high-risk profile, the severe symptoms, and the patient's wishes, a decision was made to perform a transventricular mitral repair. The patient was fully informed of the experimental procedure and that this would be a first-in-human procedure. The patient signed specific consent and the procedure was approved by the institution. Through a left minithoracotomy and a posterolateral left ventriculotomy (between the 2 papillary muscles), 3 expanded polytetrafluoroethylene neochords were attached to the free edge of the prolapsing A2 segment by means of the NeoChord device, under real-time guidance by transesophageal echocardiography (Figure 2, A). After tensioning, the prolapse was eliminated; however, moderate-to-severe mitral regurgitation persisted because of lack of coaptation between A2 and P2.
One end of each neochord was then secured to one of the long sides of a properly shaped rectangular pericardial patch (Cardiocel; Admedus, Toowong, Queensland, Australia), as depicted in Figure $2 A-C$. These neochords became functionally 3 new secondary chords. Three more neochords were then attached to the other long side of the patch, which became the new free edge of the anterior mitral leaflet (Figure 2,D). These neochords became the new-first order chords.

The patch was then hoisted inside the left ventricle by gently pulling on the 3 neochords until it was positioned against the ventricular side of the anterior mitral leaflet (Figure 2,E). This effectively created an anterior leaflet augmentation (Figure 2, F).

The final result of the procedure showed mild to moderate mitral regurgitation (Figure 1, C) remaining as a result of some degree of incomplete coaptation and a small regurgitant orifice between the patch and the free edge of the anterior leaflet. The patch was clearly seen at the transesophageal echocardiography (Figure 1,D). Video 1 shows all principal steps of the procedure.

The procedure time was about 120 minutes, the postoperative course was uneventful, and the patient was discharged home 6 days after the procedure. As of 9-month echocardiographic follow-up, the residual mitral regurgitation is stable at mild to moderate and the patient has significantly improved to New York Heart Association functional class II (Figure 1, $E$ and $F$ ). This case represents the first reported successful off-pump beating-heart anterior mitral leaflet augmentation.

\section{References}

1. Seeburger J, Rinaldi M, Nielsen SL, Salizzoni S, Lange R, Schoenburg M, et al. Off-pump transapical implantation of artificial neo-chordae to correct mitral regurgitation: the TACT Trial (Transapical Artificial Chordae Tendinae) proof of concept. J Am Coll Cardiol. 2014;63:914-9.

2. Colli A, Manzan E, Aidietis A, Rucinskas K, Bizzotto E, Besola L, et al. An early European experience with transapical off-pump mitral valve repair with NeoChord implantation. Eur J Cardiothorac Surg. 2018;54:460-6.

3. Kiefer P, Meier S, Noack T, Borger MA, Ender J, Hoyer A, et al. Good 5-year durability of transapical beating heart off-pump mitral valve repair with neochordae. Ann Thorac Surg. 2018;106:440-5.

4. Salizzoni S, Marro M, Rovera C, Speziali G, Rinaldi M. Off-pump NeoChord mitral valve repair to simultaneously treat posterior leaflet prolapse and systolic anterior motion. Ann Thorac Surg. 2017;103:e29-30. 